\title{
EFFECT OF COMMERCIAL CROSSBREEDING AND GROWTH INTENSITY ON SLAUGHTER INDICATORS, MICROSTRUCTURE AND THE QUALITY CHARACTERISTICS OF BICEPS BRACHII MUSCLE IN BULLS*
}

\author{
Krzysztof Młynek ${ }^{1}$, Adam Oler ${ }^{2}$, Beata Głowińska ${ }^{3 \bullet}$ \\ ${ }^{1}$ Department of Cattle Breeding and Milk Evaluation, Siedlce University of Natural Sciences \\ and Humanities, Prusa 14, 08-110 Siedlce, Poland \\ ${ }^{2}$ Department of Cattle Breeding, University of Technology and Life Sciences, \\ Mazowiecka 28, 85-084 Bydgoszcz, Poland \\ ${ }^{3}$ Department of Animal Physiology, University of Technology and Life Sciences, \\ Mazowiecka 28, 85-084 Bydgoszcz, Poland, \\ •Corresponding author: bglow@utp.edu.pl
}

\begin{abstract}
The commercial crossbreds with various genotypes and different growth rates in terms of the fattening and slaughter value as well as the microstructure and the quality characteristics of musculus biceps brachii were investigated. The experiment involved 38 bulls: 20 crossbreds obtained from Polish Black-and-White Lowland dams (BW) sired by Limousin bulls (LIM) - group I, and 18 crossbreds obtained from BW cows and Simmental bulls (SIM) - group II. The animals of both groups were divided into low growth rate (LG I and LG II; daily weight gain $\leq 900$ g/day) and high growth rate category (HG I and HG II; >900 g/day). The results show that significantly better dressing percentage and carcass conformation (based on the EUROP carcass classification system) were attained by BW $\times$ LIM hybrids. The genotype of bulls did not influence the content of valuable cuts in carcass and meat content of cuts, as well as most characteristics of the meat quality. The differences $(\mathrm{P}<\mathbf{0 . 0 5})$ in anaerobic index were noticed in both genetic groups of bulls in the two growth rate categories. The findings presented in the experiment also show that the number of bulls with giant fibres (GF) and the size of GF was greater in more intensively growing bulls $(\mathrm{P}<\mathbf{0 . 0 5})$ and it probably determined the higher values of tenderness and acidity of biceps brachii muscle. It should be noticed that the increased growth rate of bulls may result in poorer quality of meat.
\end{abstract}

Key words: bulls, commercial crossbreeding, growth rate, muscle microstructure, beef quality

The final economic effect of slaughter cattle production is determined by the price the producer will be given, reflecting the quality of the slaughter raw material.

*Work financed from the author's project No. 580/94/W. 
The factors that determine the beef quality resulting from the conditions of farming and breeding are mostly the genotype, nutrition, the production type, gender, age and the body weight of the animals slaughtered (Bruns et al., 2004; Młynek and Guliński, 2007; Dunner et al., 2013). The quality characteristics of meat are also affected by natural differences between muscles due to their anatomy and the physiological function played. The need for a continuous improvement of beef quality, forced by consumers, intensifies the livestock production and this can be associated with the changes in muscle microstructure reflected, for example, in the occurrence of giant fibres. They are clearly larger when compared with other fibres found in the bundle, they are oval in shape and research has shown them to affect the meat quality (Swan and Boles, 2002; Młynek et al., 2006 a; Schubert-Schoppmeyer et al., 2008). According to Wegner et al. (2000), both the amount and the size of muscle fibres determine the acidification and tenderness of meat after slaughter. The acidity and tenderness together with water holding capacity as well as the meat colour make up the basic quality characteristics essential for both consumers and the processing industry (Wegner et al., 2000; Vestergaard et al., 2000).

The hypothesis of the present research was that the differences in fattening performance, slaughter indicators, histological and physicochemical traits of muscle are connected with the genotype and growth rate of bulls. Therefore, the experiment was arranged to compare the commercial crossbreds with various genotypes and different growth rates in terms of the fattening and slaughter value as well as the microstructure and the quality characteristics of biceps brachii muscle.

\section{Material and methods}

The experiment involved 38 bulls: 20 commercial crossbreds obtained from Polish Black-and-White Lowland dams (BW) sired by a Limousin bull (LIM) - group I, and 18 crossbreds obtained from BW cows and a Simmental bull (SIM) - group II. The animals in all groups derived from two herds and within each breed group one sire was used. Throughout the fattening period the bulls were tethered indoors in individual stalls, on shallow litter. They had access to fresh water and they were individually fed. The feed was administered twice every $24 \mathrm{~h}$, with the same amount in the morning and in the evening. In the autumn-winter period all the animals were fed hay (ad libitum), corn silage (10 kg daily) and compound cereal meal (1 kg daily), and in summer they received green fodder (ad libitum), crushed cereal grain and a small addition of hay. The diets were formulated according to INRA feeding standards with the use of INRAtion software, version 2.x.x., drawing on the earlier chemical analysis of feeds and calculating their nutritive value. The animals were fed with rations that provided their maintenance requirement. The total requirements for nutrients were determined based on the INRA system. On the basis of the gain and fattening time, the animals of both groups were divided into low growth rate category, with daily body weight gain $\leq 900 \mathrm{~g}$ (LG I, LG II) and high growth rate $>900 \mathrm{~g} /$ day (HG I, HG II). The time of cattle transport to the slaughterhouse was 
approximately 3 hours. After a 24-h rest, bulls were weighed and then slaughtered. After post-slaughter carcass processing, their conformation was classified according to the EUROP system and the weight of the hot carcass was recorded. The dressing percentage was calculated as $100 \times$ hot carcass weight/slaughter weight. Within 30 min postmortem the tissue section of the middle part of biceps brachii muscle (MBB) was taken for histochemical analysis and immediately frozen in liquid nitrogen. Histochemical reactions differentiating muscle fibres into STO (slow-twitch oxidative; 'red' type), FTO (fast-twitch oxidative-glycolitic; 'intermediate' type) and FTG (fast-twitch glycolytic; 'white' type) were performed according to the Ziegan method (1979). The analysis of the muscle microstructure was performed based on the measurements recorded for 10 randomly selected muscle bundles. The analysis included: fibre type distribution (\%STO, FTO and FTG), the calculation of anaerobic index $-\mathrm{AnF} \%(\mathrm{FTG}+\mathrm{FTO} / \mathrm{STO})$, mean fibre area $\left(\mathrm{MFA} \mu \mathrm{m}^{2}\right)$, number of giant fibres (GF) and cross-section area for giant fibres (CSA - GF $\mu \mathrm{m}^{2}$ ). The $\mathrm{pH}$ was measured $24\left(\mathrm{pH}_{24}\right), 48\left(\mathrm{pH}_{48}\right)$ and 144 hours $\left(\mathrm{pH}_{144}\right)$ postmortem using the HI 98150 pH-meter (HANNA Instruments, Woonsocket, RI, USA) with a glass electrode. The meat colour was estimated using Minolta Chroma Meter CR-310 HUNTER LAB system (Minolta Camera Co., Ltd., Osaka, Japan) and concerned samples $(1.0 \mathrm{~cm}$ thick slices) taken after $48 \mathrm{~h}$ carcass cooling at $4^{\circ} \mathrm{C}$. In the same samples water holding capacity (WHC) was evaluated according to the Pohja and Niinivaara method (1957) and it was expressed as a percentage of free water in meat. The natural drip loss was determined according to Prange et al. (1977). The thermal drip loss was defined as the difference between the sample weight before and after heating, after thermal treatment of the samples (in thin-walled plastic bags) in the water bath at $75^{\circ} \mathrm{C}$. After $1 \mathrm{~h}$, the samples were cooled in tap water $\left(4^{\circ} \mathrm{C}\right)$ and then stored to reach room temperature. The meat tenderness was measured based on shear force with the use of a Warner-Bratzler knife. Samples were prepared by cutting lengthwise to the myofibres (blocks about $5 \mathrm{~cm}$ long, $1 \mathrm{~cm}$ high and $1 \mathrm{~cm}$ wide) and then were sheared perpendicular to the longitudinal axis of the muscle fibres. The mean value of 3 replicate analyses of the same sample was expressed in $\mathrm{N} / \mathrm{cm}^{2}$.

Data were statistically analysed using the SAS (2012) by analysis of variance. The model included: genetic group, growth intensity and fixed effect (genetic group $\times$ growth intensity). The tables give the least square means (LSM), the standard error of the mean (SEM), the level of significance of the effects and interactions. Differences between group means were tested by Tukey's method (level of significance set at 5\%).

\section{Results}

The animals from group II were younger by about 23-25 days as compared with group I, but the results did not differ significantly. The data show that in the case of body weight gain and carcass weight the differences between commercial hybrids in high growth rate category were significant. As for the value of valuable cuts content 
in carcass, a significant difference appeared between genetic groups of bulls in the low growth rate category (LG I, LG II). The simultaneous effect of the bull genotype and growth rate on the dressing percentage and carcass conformation was observed $(\mathrm{P}<0.05)$.

The highest content of STO fibres appeared in intensively growing bulls representing group I (HG I) and the differences, in comparison with LG I and LG II animals, were significant. The percentage of the FTO was very similar in all the animals and no significant differences were found. The influence of the growth rate on FTG fibre frequency was significant and concerned the animals with the same genotype but also occurred between groups LG I and LG II. The differences $(\mathrm{P}<0.05)$ in AnF were noticed in both genetic groups of bulls in the two growth rate categories. The effect of the bull genotype on the mean fibre area (MFA) was observed, and in $\mathrm{BW} \times \mathrm{SIM}$ crossbreds the difference between growth rate categories was also noticed $(\mathrm{P}<0.05)$. The number of fibres per bundle was lower in HG I and HG II animals in comparison with LG I and LG II, respectively. Only in BW $\times$ LIM hybrids was the difference between growth rate categories significant. However, the effect of the bull genotype on the number of fibres per bundle was observed. The differences between LG I - LG II and HG I - HG II were significant. The number and the percentage of bulls with giant fibres were highest in more intensively growing animals $(\mathrm{BW} \times \mathrm{LIM})$. In the same group of bulls the number of GF per bundle was highest and the difference concerned animals with the same genotype (LG I) as well as both growth rate categories in group II. The results showed that content of GF was lowest in LG II bulls and in BW $\times$ SIM hybrids, and the growth rate did not affect the number of GF per bundle. The muscle of the animals in the high growth rate categories contained GF with a greater cross-section area (CSA-GF) and, as compared with low growth rate, the differences occurred in both groups of commercial hybrids $(\mathrm{P}<0.05)$. A genetically determined significant difference in CSA-GF characteristic was noticed between groups I and II in the low growth rate category.

The values of tenderness were greatest in more intensively growing animals and in both genetic groups the differences between low and high growth rate categories were significant $(\mathrm{P}<0.05)$. The same tendency concerned the natural and thermal drip parameters but in the case of thermal drip also a significant breed-dependent difference was found. The effect $(\mathrm{P}<0.05)$ of growth rate on the percentage of WHC was observed. The values in low growth rate categories of both groups of crossbreds were significantly lower than in HG I and HG II bulls, respectively. The acidification of the muscle measured 24 and 48 hours postmortem showed the increase $(\mathrm{P}<0.05)$ in more intensively growing animals of both genetic groups. The same tendency concerned $\mathrm{pH}_{144}$ of $\mathrm{BW} \times \mathrm{LIM}$ group but in the case of $\mathrm{BW} \times \mathrm{SIM}$ the acidification of muscle in more intensively growing bulls (HG II) was lower. The MBB colour of the bulls from HG I and HG II category was darker (lower L* value) than in the low growth rate categories. The differences were significant $(\mathrm{P}<0.05)$ in both genetic groups. In the case of characteristic $\mathrm{a}^{*}$, the values were very similar in all the animals and no significant differences were found. 


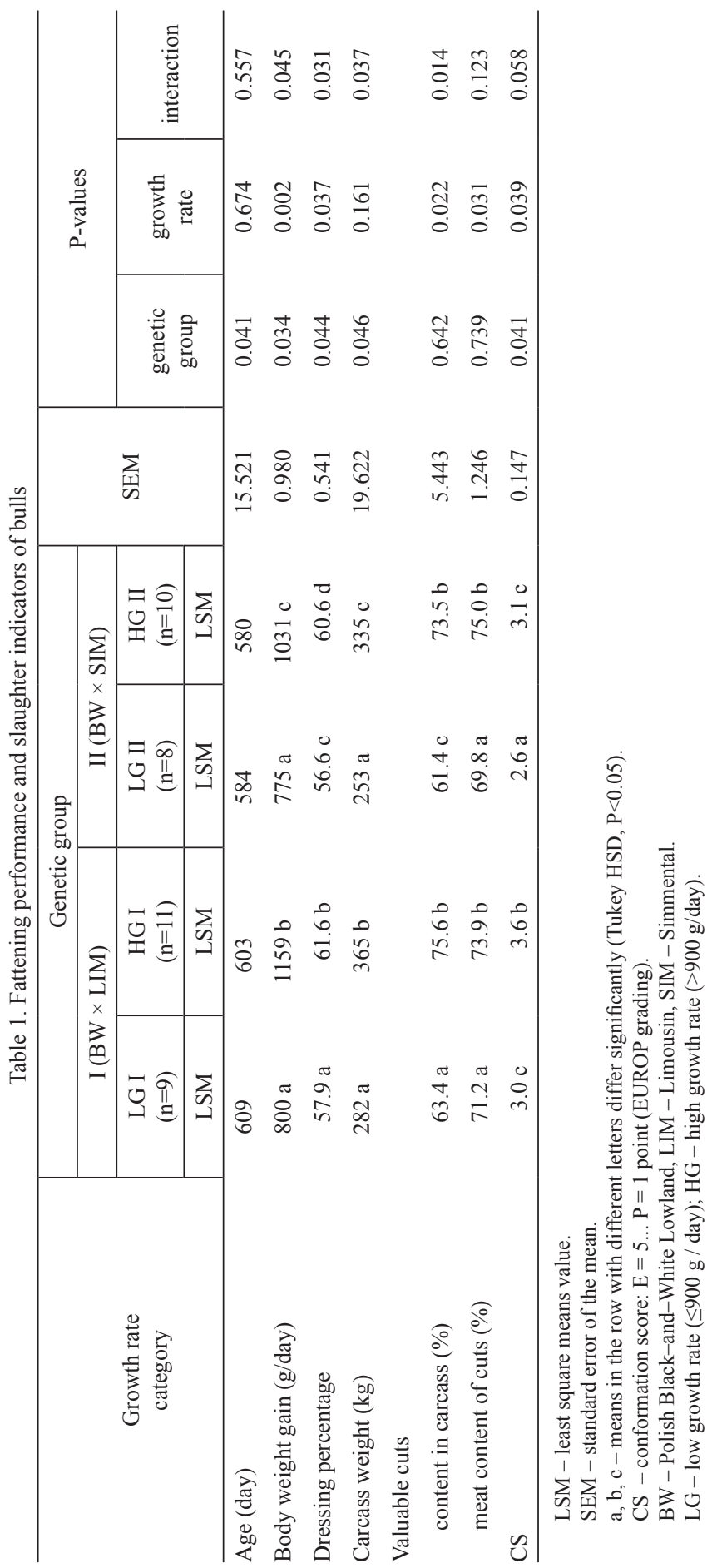




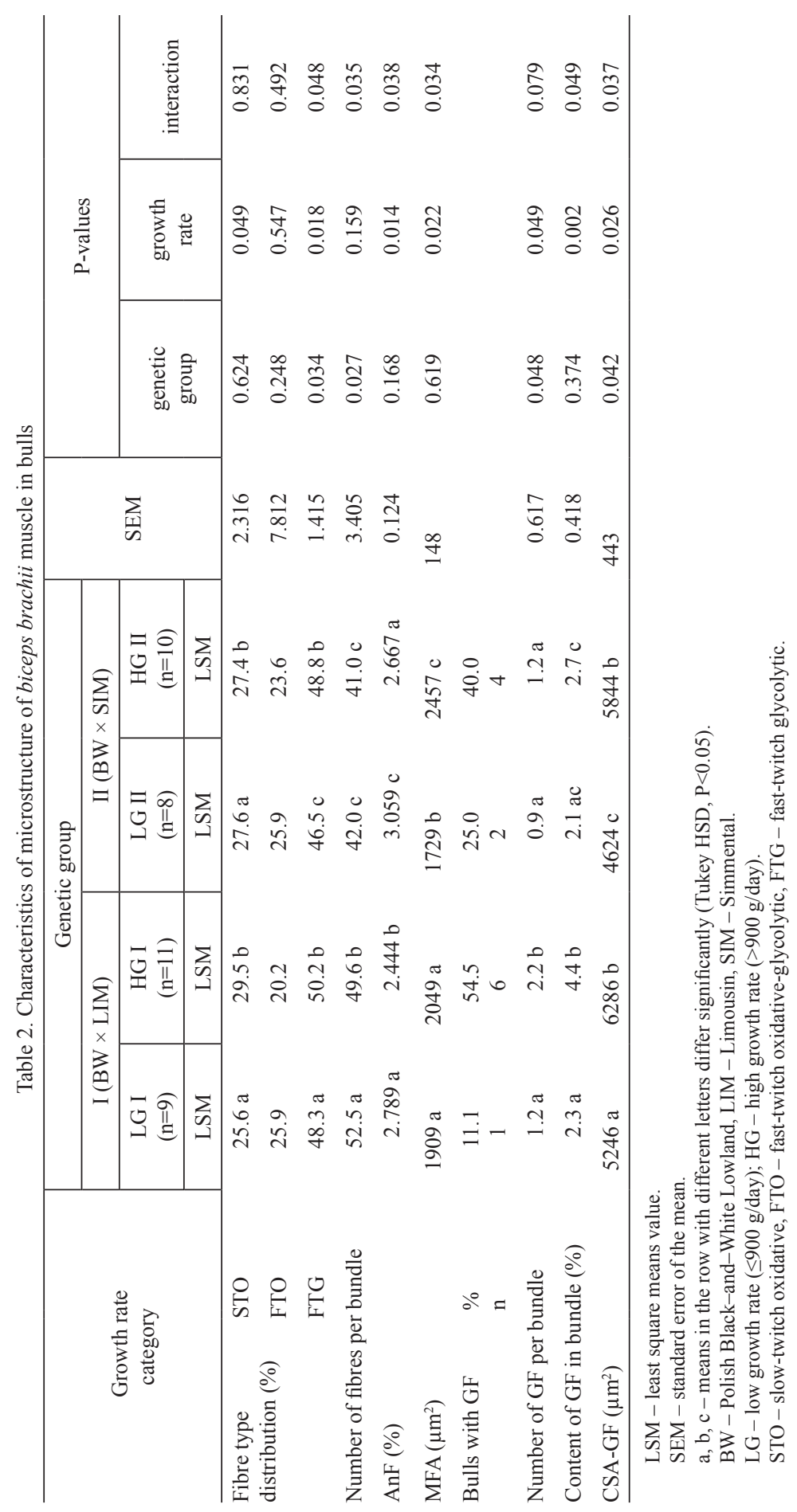




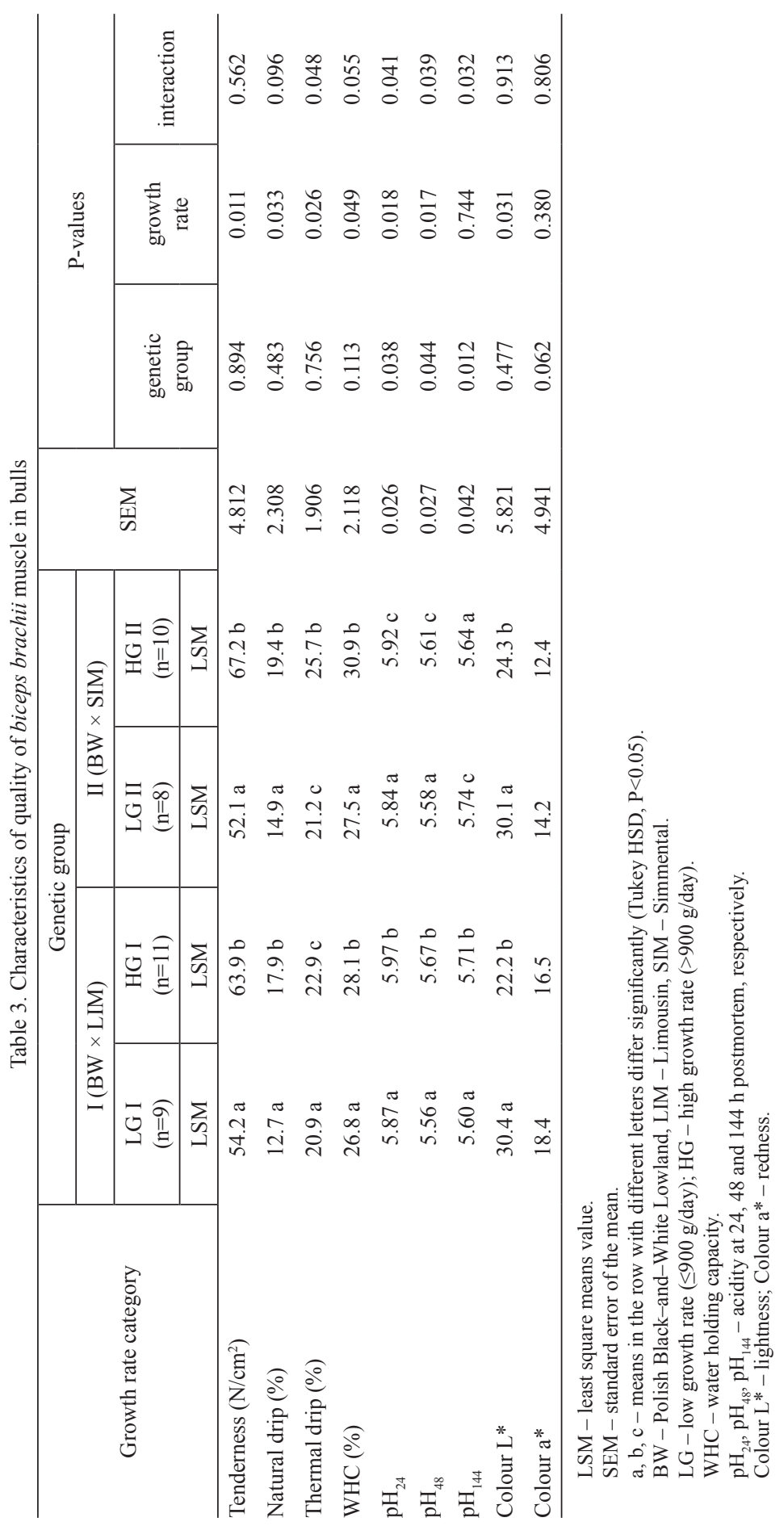




\section{Discussion}

Of all the genetic factors the breed and potential for growth are most important factors affecting slaughter characteristics, carcass composition and the meat quality (Oprządek et al., 2001; Młynek and Guliński, 2007; Nogalski et al., 2013). The differences in the carcass weight across the four cattle breeds with different muscle growth potential (slaughtered at 18 months of age) were reported by Wegner et al. (2000). The data concerning the parameter tested differ $(\mathrm{P}<0.05)$ between German Angus (GA) and Galloway (G) breeds and Holstein Friesian (HF) - Galloway. The value of carcass weight in double muscled Belgian Blue (BBDM) reached $395.5 \mathrm{~kg}$ and it was significantly higher than in GA, G and HF breeds (330.2, 262.3 and $317.8 \mathrm{~kg}$, respectively). Pesonen et al. (2012) showed the carcass weight of the Limousin bulls to be 10 and $12 \%$ higher than that of the Aberdeen Angus $\times$ Limousin and Aberdeen Angus bulls, respectively. The genetically determined carcass weights are in agreement with our finding between the crossbreds of high growth rate. The dressing percentage and percentage of the meat content of valuable cuts in intensively growing crossbreds in the present experiment coincides with the results reported by Keane and Allen (1998). They noted a significant difference in the meat content of cuts in more intensively fattened bulls. Oprządek et al. (2001) found significantly higher values of this parameter in Limousin and Charolais bulls as compared to Angus, Hereford, Simmental and Piedmontese Black-and-White F1 crosses. The higher carcass conformation class of HG I and HG II bulls compared to low growth rate category with the same genotype coincides with higher carcass weight and the results coincide with the findings of Młynek et al. (2006 a), Węglarz (2010) and Pesonen et al. (2012). Genetically determined scores for conformation were noticed by Chambaz et al. (2003). They reported that the Limousin steers demonstrated higher conformation scores compared to the Angus breed. In the present experiment there were also observed breed-dependent differences in the carcass conformation score. Similarly, as observed by Wegner et al. (2000), Młynek and Guliński (2007), and Młynek et al. (2012), the percentage of FTG fibres was significantly affected by the growth rate and it was higher in the intensively growing animals. The distribution of fibres in muscle depends on the transformation of 'intermediate' (FTO) and 'red' (STO) type of fibres into the 'white' type (FTG). In the study of Młynek and Guliński (2007) the frequency of STO fibres of longissimus dorsi muscle varied significantly from 32.0 for commercial crossbreds with the daily body weight gain $>900 \mathrm{~g}$ to 30.3 for Black-and-White bulls. As for the animals with the daily body weight gain $<900 \mathrm{~g}$, the values varied from 31.4 to $30.5 \%$, respectively. In our study we found an increase in STO content only in BW $\times$ LIM crossbreds with a high growth rate. The great variability and no differences in FTO fibres of MBB can be explained by their transformation to STO or FTG types. Ozawa et al. (2000) claimed a significant correlation between the growth intensity and the fibre structure and the size of $m$. longissimus thoracis of Japanese Black steers. In agreement with our findings Młynek et al. (2012) found GF in m. longissimus lumborum of more intensively growing bulls. Contrary to our study, they did not identify GF in the low growing rate category of bulls at all. The MFA of high growth rate animals in the study cited was signifi- 
cantly larger and it corresponds with our results in $\mathrm{BW} \times \mathrm{SIM}$ bulls. The decrease in AnF parameter showed the predominance of anaerobic metabolic transformation consisting of muscle glycogen degradation in the MBB of the intensively growing animals. The changes are in line with the results recorded by Młynek et al. (2012) in $m$. longissimus lumborum of two growth rate categories of bulls. Rehfeldt et al. (2000) concluded that the number of fibres is shaped by embryonic development and not associated with the postnatal growth period but with the genetic potential of cattle breeds, which coincides with our breed-dependent findings for the number of fibres and MFA of MBB. Młynek et al. (2006 b) showed an increased size of GF (average CSA was $5242 \mu \mathrm{m}^{2}$ ) in the $m$. longissimus lumborum of commercial crossbreds, as compared with black-and-white bulls. As reported by Crouse et al. (1991), the average muscle fibre size is correlated with beef tenderness. The differences in tenderness that occurred in our study among biceps brachii muscles are in line with the observations by Ozawa et al. (2000) who demonstrated that the meat of animals farmed less intensively revealed better tenderness. Similarly to our observations, the study of Pesonen et al. (2012) showed that breed had no significant effects on the tenderness (evaluated with the use of sensory analysis) of the m. longissimus lumborum of purebred Aberdeen Angus and Limousin and Aberdeen Angus $\times$ Limousin crossbred bulls. In agreement with our findings they also observed no influence of genotype on natural drip loss. By contrast, Chambaz et al. (2003) noted that Angus steers had lower natural drip loss than Limousin. In the study conducted by Ozawa et al. (2000) the meat of heifers growing less intensively recorded the lowest value of thermal drip. The results are similar to those presented in our study. The data reported in the present experiment for acidity of MBB are comparable to the findings of Ozawa et al. (2000), Młynek et al. (2006 a) and Młynek and Guliński (2007) who recorded increased $\mathrm{pH}$ values in the animals with a greater growth rate. Unlike our study, Chambaz et al. (2003) observed that the muscle $\mathrm{pH}$ was not affected by the genotype of animals. As for the meat colour, our results coincide with Pesonen et al. (2012) who found no significant effect of the breed on the lightness (L*) of the $m$. longissimus lumborum but the muscle redness (a*) was $13 \%$ higher in Aberdeen Angus $\times$ Limousin than in Limousin bulls. Młynek and Guliński (2007) noted that in the crossbreds slaughtered at the age of 22 months, the increased growth rate results in lower redness of meat. Węglarz (2010) reported that the weight at slaughter did not affect the meat colour parameters of meat from Holstein-Friesian bulls.

In conclusion, the results show that significantly better dressing percentage and carcass conformation (based on the EUROP carcass classification system) were attained by BW $\times$ LIM hybrids. The genotype of bulls did not influence the content of valuable cuts in carcass and meat content of cuts, as well as most characteristics of the meat quality. The findings presented in our experiment also show that the number of bulls with giant fibres (GF) and the size of GF (CSA-GF) were greater in more intensively growing bulls and it probably determined the higher values of tenderness (tougher meat) and acidity of biceps brachii muscle. It should be noticed that the increased growth rate of bulls may result in poorer quality of meat, and it is, therefore, an important consideration for beef producers. 


\section{References}

B runs K.W., Pritchard R.H., B o g g s D.L. (2004). The relationships among body weight, body composition, and intramuscular fat content in steers. J. Anim. Sci., 82: 1315-1322.

Chambaz A., Scheeder M.R.L., Kreuzer M., Dufey P.A. (2003). Meat quality of Angus, Simmental, Charolais and Limousin steers compared at the same intramuscular fat content. Meat Sci., 63: 491-500.

Cro u s e J.D., K o o h m a r a i e M., S e i d e m a n S.D. (1991). The relationship of muscle fibre size to tenderness of beef. Meat Sci., 30: 295-302.

Dunner S., Sevane N., García D., Cortés O., Valentini A., Williams J.L., Mangi n B., Cañón J., Levézi el H., the GeMQual Consortium. (2013). Association of genes involved in carcass and meat quality traits in 15 European bovine breeds. Livest. Sci., 154: 34-44.

K e a n e M.G., A 11 e n P. (1998). Effects of production system intensity on performance, carcass composition and meat quality of beef cattle. Livest. Prod. Sci., 56: 203-214.

Mły n e k K., G u liń s k i P. (2007). The effect of growth rate and age at slaughter on dressing percentage and colour, pH48 and microstructure of longissimus dorsi muscle in Black-and-White (BW) bulls vs commercial crossbreds of BW with beef breeds. Anim. Sci. Pap. Rep., 25: 65-71.

Młynek K., Elminowska-Wenda G., Guliński P. (2006 a). The relationship between microstructure of Longissimus lumborum muscle and carcass quality of bulls slaughtered at three ages. Anim. Sci. Pap. Rep., 24: 57-63.

Młynek K., Elminowska-Wenda G., Guliński P. (2006 b). Dark beef and microstructure characteristics in pure breed and crossbred animals. Anim Sci., Suppl., 1: 24-25.

Młyn e k K., J a n i u k I., D zi d o A. (2012). Effect of growth intensity of bulls on the microstructure of musculus longissimus lumborum and meat quality. Acta Vet. Brno, 81: 127-131.

Nogalski Z., Wroński M., Wielgosz-Groth Z., Purwin C., Sobczuk-Szul M., P u rw in C., W in a r s k i R., N i e dź w i e d ź J. (2013). The effect of carcass conformation class (EUROP system) on the slaughter quality of young crossbred beef bulls and Holstein-Friesians. Ann. Anim. Sci., 1: 121-131.

Oprządek J., Dymnicki E., Oprządek A., Słoniewski K., Sakowski T., Reklew s k i Z. (2001). A note on the effect of breed on beef cattle carcass traits. Anim. Sci. Pap. Rep., 19: 79-89.

Ozaw a S., Mitsuhashi T., Mitsumoto M., Matsumoto S., Itoh N., Itagaki K. et al. (2000). The characteristics of muscle fibre types of longissimus thoracis muscle and their influences on the quantity and quality of meat from Japanese Black steers. Meat Sci., 54: 65-70.

P e s o n en M., Honkava a a M., Hu us k on en A. (2012). Effect of breed on production, carcass traits and meat quality of Aberdeen Angus, Limousin and Aberdeen Angus $\times$ Limousin bulls offered a grass silage-grain-based diet. Agric. Food Sci., 21: 361-369.

Pohj a M.S., Ni in iv a r a F.P. (1957). Die Bestimmung der Wasserbindung des Fleisches mittels der Konstantdrückmethode. Fleischwirtschaft, 9: 193-195.

Prange H., Juggrt L., S charner E. (1977). Untersuchungen zur Muskel Fleischqualitaet beim Schwein (in German with English summary). Archives Experim. Vet. Med., 30: 235-248..

R e h f e ld t C., F i e d l e r I., D i e 1 G., En d e r K. (2000). Myogenesis and postnatal skeletal muscle cell growth as influenced by selection. Livest. Prod. Sci., 66: 177-188.

S chubert-Schoppmeyer A., Fi edler I., Nürnberg G., Jon as L., Ender K., Maak S. et al. (2008). Simulation of giant fibre development in biopsy samples from pig longissimus muscle. Meat Sci., 80: 1297-1303.

S w a n J.E., B o le s J.A. (2002). Processing characteristics of beef roasts made from high and normal $\mathrm{pH}$ bull inside rounds. Meat Sci., 62: 399-403.

Ve s t e r g a a r d M., O k s b j e r g N., H e n c k e l P. (2000). Influence of feeding intensity, grazing and finishing feeding on muscle fibre characteristics and meat colour of semitendinosus, longissimus dorsi and supraspinatus muscles of young bulls. Meat Sci., 54: 177-185.

Wegner J., Albrecht E., Fiedler I., Teuscher F., Papstein H.J., Enderr K. (2000). Growth- and breed-related changes of muscle fibre characteristics in cattle. J. Anim. Sci., 78: $1485-1496$. 
W ę g l a r z A. (2010). Quality of beef from Polish Holstein-Friesian bulls as related to weight at slaughter. Ann. Anim. Sci., 4: 467-476.

Zi e ga n J. (1979). Combinations of enzyme histochemical methods for differentiating of fibre types and evaluating the skeletal musculature (in German with English summary). Acta Histochem., 65: 34-40.

Received: 29 VIII 2013

Accepted: 17 I 2014 